\title{
Os Ideais da Justiça Restaurativa perante o Sistema Convencional de Justiça: Avanços trazidos pelos Juizados Especiais Criminais
}

\author{
Los Ideales de la Justicia Restaurativa ante el Sistema Convencional de \\ Justicia: Avances traídos por los Juzgados Especiales Criminales
The Ideals of Restorative Justice before the Conventional System of Justice: Advances brought by the Special Criminal Courts

\author{
Mateus de Moraes Basilio ${ }^{1}$
}

\begin{abstract}
Resumo
O presente trabalho tem como objetivo promover a reflexão sobre a necessidade de novos mecanismos complementares ao modelo tradicional de justiça penal. Tendo em vista as limitações do modelo tradicional de Direito Penal. Nesse contexto, a Justiça Restaurativa, que já teve uma primeira tentativa de efetivação de parte de seus princípios através dos Juizados Especiais Criminais, por meio da Lei ${ }^{\circ}$ 9.099/95, se apresenta como uma alternativa, de modo a dar maior dignidade ao ofensor, bem como, promover a participação da vítima no processo penal. Desse modo, essa perspectiva teórica contribui para implantar um Direito Penal que: a) valorize os princípios inerentes à dignidade da pessoa humana, b) que seja preocupado, não só, em aplicar uma sanção ao comportamento desviante. Destarte, este trabalho questiona o modelo tradicional, demonstrando a crise que o assola e a necessidade de encontrar novas alternativas para o Direito Penal, e dar as respostas esperadas pela sociedade, legitimando-o, outra vez, como um eficiente meio de solução de litígios. Já que o sistema convencional não mais se demonstra como único mecanismo eficiente de solução de conflitos, pois a instauração de um modelo de justiça consensual torna-se possível. Sendo assim, a presente pesquisa utiliza como instrumento metodológico a revisão da literatura científica sobre o tema proposto.
\end{abstract}

Palavras-chave: Justiça Restaurativa; Ideais Restaurativos; Direito Penal; Sistema Convencional de Justiça.

\section{Resumen}

El presente trabajo tiene como objetivo promover la reflexión sobre la necesidad de nuevos mecanismos complementarios al modelo tradicional de justicia penal. Teniendo en cuenta las limitaciones del modelo tradicional de Derecho Penal. En este contexto, la Justicia Restaurativa, que ya tuvo un primer intento de efectividad de parte de sus principios a través de los Juzgados Especiales Criminales, por medio de la Ley no 9.099 / 95, se presenta como una alternativa, para dar mayor dignidad al ofensor, así como, promover la participación de la víctima en el proceso penal. De este modo, esta perspectiva teórica contribuye a implantar un Derecho Penal que: a) valorice los principios inherentes a la dignidad de la persona humana, b) que sea preocupado, no sólo, en aplicar una sanción al comportamiento desviado. De este modo, este trabajo cuestiona el modelo tradicional, demostrando la crisis que lo asola y la necesidad de encontrar nuevas alternativas para el Derecho penal, y dar las respuestas esperadas por la sociedad, legitimándolo otra vez como un eficiente medio de solución de litigios. Ya que el sistema convencional ya no se demuestra como único mecanismo eficiente de solución de conflictos, pues la instauración de un modelo de justicia consensual se hace posible. Siendo así, la presente investigación utiliza como instrumento metodológico la revisión de la literatura científica sobre el tema propuesto.

Palabras clave: Justicia Restaurativa; Ideales Restaurativos; Derecho penal; Sistema Convencional de Justicia.

\footnotetext{
${ }^{1}$ Graduado em Direito; Universidade Católica de Pelotas - UCPel; Pelotas, Rio Grande do Sul, Brasil; autor@email.com
} 


\begin{abstract}
The present work aims to promote reflection on the need for new mechanisms complementary to the traditional model of criminal justice. In view of the limitations of the traditional model of Criminal Law. In this context, the Restorative Justice, which has already had a first attempt to enforce part of its principles through the Special Criminal Courts, through Law 9.099 / 95, presents itself as an alternative, in order to give greater offense to the offender, as well as to promote the participation of the victim in criminal proceedings. Thus, this theoretical perspective contributes to the implementation of a Criminal Law that: a) values the principles inherent in the dignity of the human being, b) that is not only concerned with applying a sanction to deviant behavior. Thus, this work questions the traditional model, demonstrating the crisis that plagues it and the need to find new alternatives for Criminal Law, and to give the expected responses by society, legitimating it once again as an efficient means of resolving disputes. Since the conventional system is no longer demonstrated as the only efficient mechanism of conflict resolution, since the establishment of a model of consensual justice becomes possible. Therefore, the present research uses as a methodological instrument the revision of the scientific literature on the proposed theme.
\end{abstract}

Keywords: Restorative Justice; Restorative Ideals; Criminal Law; Conventional System of Justice.

\title{
1. Introdução
}

O presente trabalho tem por objetivo realizar uma análise acerca da crise que assola o nosso sistema criminal tradicional, este que não mais consegue ser eficiente em apresentar as esperadas soluções para os litígios que são submetidos a sua jurisdição, defendendo a inserção da regulamentação de um mecanismo de justiça consensual que possibilite dar um tratamento mais efetivo na solução de conflitos, principalmente no que se refere aos crimes de menor potencial ofensivo.

A Justiça Restaurativa se apresenta como sendo essa alternativa, possibilitando uma maior participação da vítima no processo de resolução dos litígios, já que esta, no decorrer da formação da nossa justiça penal atual, foi relegada a uma posição secundária, não tendo mais seus interesses satisfeitos, com o Estado assumindo o papel de principal afetado pela conduta delituosa. Nosso Código Penal foi estabelecido partindo dos ideais de uma justiça penal retributiva, que visa a retribuição do mal praticado, aplicando a sanção penal correspondente ao ofensor, de acordo com comportamento desviante praticado. Essa lógica não se preocupa com a complexidade envolvida em cada conflito, não permitindo a vítima uma participação efetiva, onde não há a possibilidade de esta aceitar uma conciliação que lhe poderia ser útil.

Nosso ordenamento jurídico já deu um primeiro passo em direção a regulamentação de um mecanismo consensual para a solução dos conflitos existentes na nossa sociedade, esse primeiro passo foi representado pela promulgação da Lei $n^{\circ} 9.099 / 95$, que regulamentou o funcionamento dos Juizados Especiais Criminais. Ressalvada a importância desse passo, se levado em consideração que, na época, nosso ordenamento jurídico caminhava para uma direção de um maior endurecimento do Direito Penal, com a promulgação da Lei dos Crimes 
Hediondos, os Juizados Especiais Criminais não conseguiram implantar muitos de seus ideais, similares aos defendidos pela Justiça Restaurativa, esbarrando em mecanismos tradicionais presentes em nosso sistema. Nessa situação, os Juizados Especiais funcionaram mais como um mecanismo administrativo do sistema tradicional, diminuindo o número de processos que tramitavam nas varas criminais comuns.

Apesar de os Juizados Especiais Criminais não terem obtido todo o sucesso esperado, implementando todos os seus ideais, estes criaram importantes mecanismos como a conciliação, a transação penal e a suspensão condicional do processo, como será visto no decorrer deste trabalho. A sua regulamentação demonstra que os operadores do direito enxergam a necessidade de serem realizadas mudanças no sistema convencional de justiça que rege a nossa sociedade até então, devendo haver a apresentação de alternativas capazes de solucionar os problemas que o nosso sistema, sozinho, não é capaz de solucionar.

A Justiça Restaurativa, por intermédio de seus ideais restaurativos, não visa a eliminação do Direito Penal, pois entende que este ainda se faz necessário no que tange aos conflitos penais de maior gravidade, onde a aplicação de uma sanção penal mais severa se faz imprescindível, mas, pretende ser uma alternativa que o complemente, solucionando determinados litígios de uma forma mais eficiente, através de mecanismos consensuais, de forma que o sistema convencional de justiça é incapaz de proporcionar. Todavia, apesar de haverem posicionamentos contrários a essa despenalização, dando ênfase aos mecanismos consensuais, é dominante o entendimento de que este é o melhor caminho para combater a crise do sistema atual, vislumbrando que não há qualquer efeito positivo na aplicação da pena, com esta servindo para agravar ainda mais a situação, tanto do ofensor quanto da vítima, no contexto em que esses determinados delitos, de pequeno e médio potencial ofensivo, podem receber um melhor tratamento pelo nosso ordenamento jurídico.

Deve-se defender a construção de um Direito Penal mais humano, pautado pelos princípios inerentes a dignidade da pessoa humana, uma justiça penal que não se justifique pela simples aplicação de sanções a partir da prática de determinado comportamento desviante. O sistema convencional de justiça precisa ser questionado e modificado, e a Justiça Restaurativa se propõe a ser essa alternativa de modificação, transformando o Direito Penal em uma justiça mais humana, oferecendo os devidos tratamentos para satisfazer os interesses da vítima e dar ao ofensor uma verdadeira chance de se redimir perante a sociedade.

\section{Justiça Restaurativa: Origem, Definição e Características}




\subsection{Origem}

A noção de justiça vem sendo trabalhada ao longo dos tempos, com sua definição variando de acordo com a evolução moral e intelectual da sociedade de cada época. Antes de partirmos para a análise do que é a Justiça Restaurativa e, de que modo esse movimento se originou, vamos analisar as bases do sistema retributivo, como a ideia atual de justiça penal se instaurou nas relações existentes nas sociedades humanas.

O sistema retributivo tem sua legitimação na medida em que se firma como uma reação, uma resposta da sociedade para a prática de determinado ato, objetivando trazer estabilidade para as relações sociais, estabelecendo um padrão social a ser seguido. Tais execuções penais propostas por esse modelo retributivo consistem na estigmatização, exclusão, desproporção, e numa constante e incessante busca por justiça, não levando em consideração as características peculiares e complexas de cada caso onde ocorra a violação da norma, tampouco se importando com as características do ofensor, contra quem a pena é dirigida (SALIBA, 2009).

A reação social propagada pela aplicação da sanção penal acabou por selecionar os grupos sociais ou pessoas e as condutas que seriam passíveis de punição, e para as quais o sistema penal dirigiria seus esforços. Essa seleção trouxe problemas ao sistema, uma vez que foi responsável por contribuir, através de uma atribuição seletiva, para a existência de um sistema excludente. Desse modo, criou-se uma sociedade devoradora, incluindo alguns mais próximos e excluindo outros (SALIBA, 2009).

A Justiça Restaurativa tem sua origem na insatisfação social oriunda da ineficiência demonstrada pelo modelo tradicional de justiça criminal, modelo esse, que vem apresentando falhas no processo de construção da paz e da ordem social, tão almejadas nas mais diversas sociedades ao longo da história. Foram nas falhas do modelo tradicional que se buscou uma nova alternativa para a resolução de conflitos, visando-se suprimir as falhas do modelo tradicional até então instaurado (ACHUTTI, 2014).

Sendo assim, a Justiça Restaurativa surge como uma alternativa para os problemas enfrentados e não solucionados pelo modelo de justiça tradicional, podendo determinar novas diretrizes a serem seguidas no campo da Justiça Criminal, com vistas a dar uma maior efetividade, além de apresentar novas soluções, para um sistema que já se encontra tão desgastado perante a sociedade, e aos problemas que esta vem apresentando.

\subsection{Definição}


A Justiça Restaurativa pode ser considerada, de acordo com a citação de Daniel Achutti, nas palavras de Gerry Johnstone e Daniel Van Ness como "um movimento social global que apresenta enorme diversidade. O seu objetivo maior é transformar a maneira como as sociedades contemporâneas percebem e respondem ao crime e a outras formas de comportamentos problemáticos" (VAN NESS e STRONG, 2010, p.23).

Diante da dificuldade encontrada pela doutrina em definir e diferenciar aquilo que pode ser considerado Justiça Restaurativa, podemos afirmar que se trata de um conceito desenvolvido lentamente ao redor do globo, pois não temos a presença de um órgão responsável por realizar a verificação e determinação do que podemos considerar como sendo Justiça Restaurativa. Ressaltando que o conceito atualmente utilizado não foi construído dentro do movimento, mas de forma independente, tendo sido adotado por estudiosos voltados ao tema (ACHUTTI, 2014).

Dentre as definições dadas pelos teóricos sobre o que é justiça restaurativa, temos como um importante documento para nos ajudar a esclarecer um pouco mais, a Resolução n. 2002/12 da Organização das Nações Unidas. Ela torna-se muito importante na medida em que define quais são os princípios restaurativos.

Após a análise acerca da dificuldade em se construir um conceito de Justiça Restaurativa, mas, vislumbrando a necessidade de se ter uma definição, utilizaremos o seguinte conceito elaborado por Marcelo Saliba (2009, p. 148):

\begin{abstract}
justiça restaurativa pode ser conceituada como: processo de soberania e democracia participativa numa justiça penal e social inclusiva, perante o diálogo das partes envolvidas no conflito e comunidade, para melhor solução que o caso requer, analisando-o em suas peculiaridades e resolvendo-o em acordo coma vítima, o desviante e a comunidade, numa concepção de direitos humanos extensíveis a todos, em respeito ao multiculturalismo e à autodeterminação.
\end{abstract}

Ao trazermos este conceito ao trabalho, temos o objetivo de utilizá-lo como guia, propiciando uma melhor compreensão acerca do tema que será tratado, ajudando a esclarecer quais são os seus objetivos.

\title{
2.3 Características
}

Apesar da já mencionada dificuldade em estabelecermos um conceito para a Justiça Restaurativa, há a presença de determinados elementos que não podem deixar de estarem presentes para que tenhamos, efetivamente, um modelo de justiça restaurativa aplicado. A seguir, analisaremos alguns de seus pilares, considerados essenciais na caracterização desse modelo de justiça penal. 
A primordial, e talvez mais importante característica da justiça restaurativa, devendo sempre se fazer presente em qualquer procedimento restaurativo, diz respeito à mobilidade. Esta faz com que o modelo restaurativo se encaixe nos interesses sociais e comunitários dos envolvidos no conflito. Embora a mobilidade se faça essencial ao programa restaurativo, não se pode deixar de lado a necessidade de uma delimitação mínima acerca das regras que norteiam um modelo restaurativo, pois sem elas correríamos o risco de termos um desvirtuamento das ideias que pautaram o surgimento do modelo restaurativo de justiça. Dessa forma, manteremos as noções e características originais que motivaram a criação da justiça restaurativa (SALIBA, 2009)

Dentre os pilares essenciais da Justiça Restaurativa, começaremos destacando o encontro. Este pilar tem por objetivo promover o encontro entre vítima e ofensor, propiciando o diálogo entre as partes, estabelecendo uma restauração por intermédio das trocas de experiência e da análise acerca das consequiências geradas pela prática do delito (LEAL, 2014).

Outro pilar restaurativo consiste na inclusão ou participação dos envolvidos no conflito. Esta característica é responsável por formar o triângulo envolvido no processo, entre vítima, ofensor e comunidade, possibilitando o efetivo diálogo já mencionado anteriormente. É pilar essencial da Justiça Restaurativa, sem o qual o modelo restaurativo não existiria, pois não teríamos o diálogo entre as partes envolvidas no conflito (LEAL, 2014).

Agora, falaremos sobre o pilar que constitui o principal objetivo a ser almejado pelos programas restaurativos, a reparação. Esta se concretiza com a devolução ou restituição do bem que foi materialmente atingido pela prática do ilícito penal, podendo ocorrer por intermédio de indenização, do trabalho em favor da vítima, ou em favor da sua família, e também ocorrendo por meio de práticas visando ressarcir a comunidade, que fora afetada de forma secundária pela prática do delito (LEAL, 2014).

Por fim, comentaremos sobre os últimos dois pilares da justiça restaurativa, que são a reintegração e a transformação, também essenciais para que o modelo restaurativo proposto atinja a sua finalidade. A reintegração visa evitar a revitimização daquele que é colocado na condição de vítima, já que a comunidade não o acolhe devidamente durante o procedimento a que foi submetido. Tenta-se restabelecer o seu equilíbrio emocional. Quanto ao infrator, este também é alvo do processo de reintegração, com a prática restaurativa objetivando fazer com que possa entender a gravidade do ato praticado, tornando-o capaz de analisar a própria conduta, refletindo sobre o mal causado a vítima (LEAL, 2014). 
Transformar significa que não podemos apenas almejar alcançar a situação que a sociedade se encontrava antes da prática criminosa, pois para que transformemos verdadeiramente é necessário que se possibilite a criação de uma nova sociedade, que transmita uma maior segurança aos seus cidadãos, passando a confiarem nela (LEAL, 2014).

A importância dos pilares se dá na medida em que estes são os responsáveis por diferenciar a Justiça Restaurativa do atual modelo de justiça criminal, pautado pela repressão, não oferecendo um adequado meio para que tenhamos uma efetiva composição dos conflitos a ele submetidos. Portanto, podemos caracterizar a lógica restaurativa a partir de um ideal de justiça social, respeitando o ser humano e seus valores fundamentais (SALIBA, 2009).

\section{Repensando a lógica criminal do sistema criminal a partir dos fundamentos da Justiça Restaurativa e da promulgação da Lei no 9.099/95}

Uma vez analisada a Justiça Restaurativa e os seus elementos caracterizadores, procuraremos demonstrar de que modo os ideais restaurativos podem atuar na busca por uma modificação de um sistema que já se encontra tão saturado, não conseguindo mais solucionar todos os litígios submetidos a sua jurisdição. Ressaltando que, apesar das falhas, a Justiça Restaurativa não busca promover a completa substituição do modelo tradicional, mas sim sua complementação.

A lógica do sistema criminal atual é baseada em uma ideia punitivista, no qual a pena encontra como significado e finalidade a retribuição do mal praticado pelo infrator, funcionando como uma ideia de vingança, ao invés de ser estabelecida como meio de manutenção das relações sociais, visando à recuperação tanto da vítima quanto do infrator, para que ambos possam voltar a viver de forma pacifica na sociedade. Essa lógica constitui obstáculo ao nosso avanço enquanto civilização, não solucionando. As alternativas surgem para quebrar esse paradigma tradicional, tentando estabelecer nova finalidade à pena, demonstrando que esta não pode basear-se inteiramente no sentimento de vingança da sociedade contra o responsável por quebrar as normas. É dentro desse contexto anteriormente apresentado que surge a alternativa representada pela Justiça Restaurativa, objetivando a diminuição os efeitos negativos gerados a partir da aplicação da pena (SALIBA, 2009).

Visualizamos que o direito penal não é o modelo ideal de justiça, pois não consegue em todas as suas instâncias solucionar os problemas apresentados na convivência diária das pessoas dentro do grupo social, mas se faz necessário diante da necessidade de manter a liberdade e a ordem na sociedade, com situações que podem vir a exigir a tomada de medidas 
mais fortes. Dessa forma, a Justiça Restaurativa se propõe a apresentar uma alternativa, não desejando a exclusão do direito penal do atual ordenamento jurídico, propondo-se a ser essa nova opção. E o modo pelo qual deseja realizar essa alternativa é através do respeito à dignidade da pessoa humana e aos direitos humanos como um todo (SALIBA, 2009).

É nesse contexto que demonstraremos a contribuição proporcionada pelo olhar da Justiça Restaurativa, como os seus ideais podem ser aplicados juntamente ao modelo tradicional de justiça criminal, demonstrar que ambos os mecanismos de justiça podem coexistir, num cenário onde o olhar restaurativo tem as ferramentas necessárias para contribuir na eliminação das falhas da justiça criminal tradicional.

\subsection{A Justiça Restaurativa como alternativa para o Sistema Criminal Tradicional}

A Justiça Restaurativa se coloca na posição de alternativa ao modelo tradicional na medida em que nos traz uma nova visão acerca do delito, propondo uma nova concepção ao seu tratamento, demonstrando que a nossa evolução enquanto sociedade está diretamente ligada a maneira como nós reagimos ao delito, afirmando que não podemos mais apenas fomentar o sentimento de vingança, que embasa a lógica retributiva, mas que precisamos procurar uma nova vertente na resposta aos litígios, mudando a reação social.

O sistema penal foi construído ao longo das épocas como um modo de estabelecer a legitimação do Estado, além de ser um modo de atender aos interesses das classes dominantes, mantendo-as no poder. Criou-se a partir disso uma visão positivista do Direito, com este assumindo a função de definir e separar o bem e o mal, determinando quais condutas seriam consideradas boas para o convívio em sociedade e quais seriam consideradas inaceitáveis, devendo obrigatoriamente serem reprimidas pelo poder estatal. Esclarecendo que o positivismo, em sua definição, preocupa-se apenas em resolver os problemas técnicos entre meios e fins, não os analisando de forma racional, esquecendo-se que, acima de tudo, o direito deve preocupar-se com o ser humano e as suas necessidades, pois o direito penal, principalmente, não pode ser constituído apenas na elaboração de leis e cominação de penas, devendo preocupar-se com a dignidade da pessoa humana em toda a sua complexidade (SALIBA, 2009).

Propomos, com os ideais defendidos pela Justiça Restaurativa, resgatar o caráter reeducativo da pena, evitando que o infrator possa sofrer os efeitos devastadores da pena, no sentido de ela apenas cumprir a função de consolidar o infrator como um criminoso perante a sociedade. A pena, na sua atual conjuntura, não proporciona ao infrator novas oportunidades, 
para que ele possa demonstrar ter aprendido com os seus erros, funcionando apena no sentido de consolidar a sua estigmatização, na figura de um criminoso, perante a sociedade (SALIBA, 2009).

Uma das causas para a crise do sistema retributivo encontra-se nas desigualdades sociais existentes nas sociedades, visto que a reação social constituiu fator indispensável para a construção do sistema penal como o temos hoje, estabelecendo diferenças sociais ao definir quais grupos ou pessoas seriam normalizadas pelo direito penal, isto é, a quem a norma penal se dirigiria. Foi a partir desse sistema que as classes dominantes passaram a normalizar as classes escolhidas, imunizando assim as classes detentoras do poder. O Direito Penal, ao longo da sua formação e consolidação, construiu uma certa atribuição seletiva, taxando o indivíduo como criminoso e que este, em virtude desta condição, não mais poderia ser recuperado, devendo, portanto, ser afastado quase que permanentemente do convívio social. Essa sistemática, não via a recuperação do infrator, mas o seu completo afastamento do círculo social. A partir disso, tivemos, ao longo de nossa história, a construção de uma sociedade devoradora e desumana, incluindo apenas uma minoria e excluindo outra, que termina por ser aquela a quem a aplicação lei penal se destina, estereotipando esse outro grupo, estabelecendo sua incapacidade de conviver em sociedade (SALIBA, 2009)

Com isso, podemos perceber que o desvio de finalidade do Direito Penal escancara a maior causa da crise do sistema retributivo, na proporção em que a função ressocializadora da pena é consequentemente, esquecida em detrimento da retribuição buscada pelo sistema, se é que, em algum momento, houve uma efetiva busca pela ressocialização do indivíduo através da aplicação da norma penal. Portanto, o autor Marcelo Saliba fundamenta a ideia antes exposta, ao citar a posição de Aniyar de Castro, esclarecendo que os fins da prisão e seus consecutivos tratamentos fracassaram no processo de concretização de seus fins explícitos, baseados na função ressocializadora e na reinserção social, mas que seus fins implícitos obtiveram o esperado sucesso, de modo em que conseguiram reproduzir um sistema de classes efetivo, deixando a classe dominante livre para realizar suas ações dentro do mercado e separando as classes delinquentes das não delinquentes, consolidando uma denominada estratificação (SALIBA, 2009).

Destarte, cabe destacar que a pena, na sua evolução histórica, terminou por não atingir o seu pilar fundamental, talvez aquele que tenha sido o responsável por motivar a sua criação, que é o do efeito de reeducar o infrator, fazendo com que este adquira as qualidades necessárias ao convívio social, mas, ao inverso, as penas, partindo da sua aplicação pelo Estado e suas instituições, tornou o infrator um ser humano pior, visto que não lhe foi dada a 
devida aplicação da pena. A pena ignorou a humanidade do infrator. Assim, a deslegitimação do sistema penal continua tendo como causa principal o seu fundamento retributivo, já que seu discurso encontra-se desacreditado, faltando a credibilidade necessária para as justificativas de sua atuação (SALIBA, 2009).

A falha no caráter da retribuição da pena pode ser resumida a partir do seguinte pensamento expresso nas palavras do autor Luigi Ferrajoli (2002, p. 310):

\begin{abstract}
mais horrenda e infamante para a humanidade do que a própria história dos delitos: porque mais cruéis e talvez mais numerosas do que as violências produzidas pelos delitos têm sido das produzidas pelas penas e porque, enquanto o delito costuma ser uma violência ocasional e às vezes impulsiva e necessária, a violência imposta por meio da pena é sempre programada consciente, organizada por muitos contra um. Frente à artificial função de defesa social, não é arriscado afirmar que o conjunto das penas cominadas a história tem produzido ao gênero humano um custo de sangue, de vidas e de padecimentos incomparavelmente superior ao produzido pela soma de todos os delitos.
\end{abstract}

Outrossim, podemos concluir que o modelo tradicional de justiça criminal, como o que temos hoje, não mais consegue suprir todos os problemas, precisando de uma devida complementação, objetivando atender as necessidades humanas em toda a sua complexidade.

A Justiça Restaurativa pode ser considerada uma filosofia de justiça centrada não apenas na violação da norma e na necessidade de se castigar o culpado, mas em uma lógica pela qual se deve buscar, sobretudo, a dimensão do dano e a forma como este será reparado em face da vítima, prejudicada pela prática infracional. Diferentemente da Justiça Restaurativa, a Justiça Retributiva errou em focar-se apenas na dimensão pública do delito, esquecendo-se da mais importante, a humana, não dando a devida importância à participação da vítima nesse processo. Assim sendo, fica evidente que ambas as formas, restaurativa e retributiva, não possuem um modo distinto de entender justiça, mas uma fundamental diferença no campo das emoções, no modo de cada filosofia canalizá-las (LEAL, 2014).

\title{
3.2 A Promulgação da Lei no 9.099/95 no contexto de uma nova lógica criminal
}

É incontestável o reconhecimento de que o sistema de justiça penal, apesar de suas diversas falhas, ainda exerce fundamental função na sociedade, tornando-se impossível a defesa de sua completa eliminação. Nesse contexto, surgiu a necessidade de se dar um novo tratamento aos crimes de médio e potencial ofensivo, visto que é função do direito penal dar respostas aos conflitos no seu sentido qualitativo e quantitativo. Desse modo, surge a necessidade de delimitação para um espaço de consenso no nosso ordenamento jurídico, evidenciando o anseio social de procurar uma nova resposta ao conflito, diferente daquela que 
se apresentava, consolidada ao longo da evolução social e cultural (MOLINA e GOMES, 2006).

A partir dessa constatação, em princípio, como forma de se implementar esse novo espaço destinado ao consenso, vislumbra-se um novo campo para se dar a aplicação de penas ou medidas alternativas, que é o tratamento utilizado para solucionar a prática dos crimes considerados de pequeno e médio potencial ofensivo. Um dos obstáculos apontados a implementação dessa nova via consensual, se baseia no fato de que esta representa um recuo em alguns direitos fundamentais, inerentes ao ser humano. Igualmente, devemos reconhecer que este é um fato verdadeiro, mas que, por si só, não obsta a sua aplicação, visto a necessidade de consolidarmos uma abordagem mais ampla aos direitos fundamentais, que não podem ser pensados apenas para o indivíduo, mas para a comunidade como um todo, já que esta também é parte beneficiada por essas garantias (MOLINA e GOMES, 2006).

É dentro desse contexto social e jurídico que temos o surgimento da Lei $n^{\circ}$ 9.099/95, que dispõe sobre os fundamentos e o funcionamento dos Juizados Especiais Cíveis e Criminais, que se encontra em vigor em todo o território nacional desde o dia 26 de novembro de 1995. Essa lei teve como inspiração a necessidade do surgimento de um modelo de política criminal voltado mais para o consenso, baseado nos princípios da simplicidade, da oralidade, da informalidade, da economia processual e da celeridade, buscando, sempre que possível, a conciliação e a transação, evitando que a resolução do conflito se desenvolva através das técnicas processuais penais tradicionais (MOLINA e GOMES, 2006).

Com a vigência da nova lei, testemunhamos uma significativa mudança no cenário jurídico brasileiro, passando a ser promovida uma reavaliação acerca do valor de justiça, transformando sua concepção de uma forma nova e revolucionária. Tais transformações ficam evidentes a partir da disposição do art. 74, parágrafo único, da Lei $\mathrm{n}^{\circ}$ 9.099/95, que prevê a extinção da punibilidade nos casos de infrações penais de menor potencial ofensivo de ação penal privada e de ação penal pública condicionada à representação da vítima. Ressaltamos a mudança promovida na medida em que ela se revela de grande valia, repensando a lógica criminal vigente, dando importância aos interesses da vítima do conflito e deixando de lado a pretensão punitiva estatal que, por sua vez, preocupa-se em demasia na condição de punir o infrator, atendendo aos interesses do Estado e das suas instituições (MOLINA e GOMES, 2006).

A nova lógica, proposta pelos Juizados Especiais Criminais, é pautada por novos princípios, que embasam esse novo modo de encarar o conflito. Dentre eles, podemos destacar o princípio da ultima ratio, que prioriza a resolução dos conflitos pela via 
consensual, colocando o direito penal como a última alternativa a ser utilizada, apenas depois de ocorrido o insucesso na tentativa de conciliar vítima e infrator. Dessa forma, fica evidenciado o caráter despenalizador proposto pela Lei $\mathrm{n}^{\circ}$ 9.099/95, afirmando que em caso de haverem outras medidas efetivas para a resolução de conflitos, devemos priorizá-los em detrimento do tratamento tradicional oferecido pelo Direito Penal. O novo dispositivo legal coloca a reparação do dano como interesse primário, retirando a prioridade dada ao poder punitivo do Estado (DEMERCIAN e MALULY, 2008).

Mencionadas as principais mudanças trazidas pela Lei $\mathrm{n}^{\circ} 9.099 / 95$ ao sistema criminal vigente, alguns de seus dispositivos, responsáveis por essas transformações, devem receber maior atenção, dentre eles destacam-se a conciliação, a transação penal e a suspensão condicional do processo, visto tratarem-se de acréscimos relevantes ao processo penal. No que se refere à transação penal, não há um entendimento pacífico acerca da sua aplicação, se ela é ou não, positiva para o transgressor da norma penal. Destarte, falaremos brevemente sobre cada um dos dispositivos.

A conciliação prevista será realizada em audiência, devendo haver o comparecimento de ambos os interessados, vítima e infrator, ocasião em que ambas as partes será esclarecidas pelo juiz acerca da possibilidade de composição dos danos e que, em caso de não aceitação da proposta realizada, será aplicada, de forma imediata, da aplicação de sanção não-privativa de liberdade, conforme disposição expressa do art. 72, da Lei nº 9.099/95. Essa audiência possui um caráter pedagógico e de prevenção geral, com consequiência que vão para além desses aspectos, havendo a possibilidade de renúncia e a consequente extinção da punibilidade, tornando o acordo obtido em audiência num título executivo judicial (DEMERCIAN e MALULY, 2008).

O dispositivo da conciliação ressalta a importância do papel da vítima na solução do conflito, através do seu art. 74, parágrafo único, estabelece que uma vez homologado o acordo em audiência, há a imediata renúncia ao direito de queixa ou representação, consolidando o entendimento da lei de que a composição dos danos é ato incompatível com o oferecimento de queixa ou representação (DEMERCIAN e MALULY, 2008).

A transação penal, em sua proposta, é pautada pela imediatidade, seguindo a tendência internacional de o Direito Penal e Processual Penal apresentarem rápidas soluções para os casos menores. É um instituto que, por sua vez, dá ao Ministério Público um poder de discricionariedade, visto que é ele o parquet o órgão responsável por oferecer a proposta de transação penal. Oferecendo a proposta, o Ministério Público abdica do seu direito de oferecer denúncia, com o réu evitando ser processado criminalmente, assim como escapa das 
consequências que possam emergir do processo penal. Tal discricionariedade terminou por ser objeto de críticas, já que poderia, ao ser aplicada, provocar tratamento diferenciado entre os réus, podendo o promotor ter um poder ilimitado de escolher quem serão os destinatários do instituto. Essa problemática é solucionada pelos autores Pedro Henrique Demercian e Jorge Maluly, a partir do posicionamento dos ilustres autores do Projeto de Lei dos Juizados Especiais, Ada Pellegrini Grinover, Antonio Magalhães Gomes Filho e Antonio Scarance Fernandes, que demonstram ser o poder discricionário dado ao promotor limitado pelo uso do bom senso, além de esclarecer estar o promotor limitado às circunstâncias judiciais que delimitam a aplicação do instituto da transação penal. Portanto, não tem os promotores poderes ilimitados como afirmam os críticos ao poder discricionário dado ao Ministério Público (DEMERCIAN e MALULY, 2008).

Ao fim, temos a presença do instituto da suspensão condicional do processo, previsto pelo art. 89 da Lei ${ }^{\circ}$ 9.099/95, na parte em que trata dos Juizados Especiais Criminais, representando uma das mais importantes inovações trazidas ao processo penal. Isso se dá devido ao fato de que o instituto soluciona um dos grandes problemas existentes no cotidiano das varas criminais, a quantidade de processos a serem analisados, pois com tal quantidade, quase que absurda, tramitando diariamente, torna-se impossível dar um resposta adequada para cada conflito, é impossível analisar cada caso com suas individualidades e complexidades necessárias (DEMERCIAN e MALULY, 2008).

Em nosso ordenamento jurídico, o instituto da transação penal tem a sua aplicabilidade em momento anterior ao do reconhecimento da culpabilidade do acusado, sem prejuízo a oportunidade de oferecimento da denúncia, com o órgão titular da ação penal podendo realizar a sua proposição, uma vez que se encontrem preenchidos todos os requisitos expressamente previstos em lei. Ressalta-se, oportunamente, que para a ocorrência da proposta de suspensão condicional do processo, é fundamental a existência de acordo entre as partes, vítima e acusado, sendo similar ao procedimento do sursis, previsto pelo nosso Código de Processo Penal. Vide o que estabelece a súmula 696 do Supremo Tribunal Federal. Sua aplicação se dá com o julgador suspendendo o processo por um período de prova, após a realização de acordo entre as partes. Com a aplicação desse instituto, procura-se dar uma resposta rápida para a sociedade, sendo apresentadas soluções ágeis para as infrações penais de menor potencial ofensivo (DEMERCIAN e MALULY, 2008).

Uma vez analisados os institutos trazidos pela Lei $\mathrm{n}^{\circ}$ 9.099/95, aplicados por intermédio dos Juizados Especiais Criminais, podemos observar claramente que a nossa 
legislação caminha em direção a uma vertente despenalizadora, aproximando-se dos ideais propostos pela Justiça Restaurativa, evidenciando a decadência do modelo atual.

\section{Os Juizados Especiais Criminais como instrumento para a concretização da aplicação dos ideais da Justiça Restaurativa}

A partir da década de 90, o direito brasileiro, com o marco da promulgação da Lei $n^{\circ}$ 8.072/90, que trata acerca dos crimes hediondos, tem se caracterizado por um considerável endurecimento, visto o aumento exponencial da prática criminosa e a falta de êxito das instituições responsáveis pelo controle da criminalidade em suas ações visando o caráter da prevenção geral. Ora, é de se esperar que tais problemas sejam alvo da busca por soluções mais efetivas, caindo-se no erro do exercício de uma legislação penal mais rígida, esquecendo-se da eficiência das penas hoje aplicadas (MOLINA e GOMES, 2006).

Dessa forma, torna-se notável o impacto e a significância produzidos pela Lei $\mathrm{n}^{\circ}$ 9.099/95, caracterizando-se esta uma vertente totalmente contrária ao que vinha sendo produzido pelo Poder Político Brasileiro. Embora tenha-se reconhecido o endurecimento das normas penais aplicadas, tal fato não se converteu na sua principal finalidade, que é a de diminuir a insegurança e os índices de criminalidade. Segundo o autor Antonio Garcia Pablos de Molina, a ideia de que o rigor da pena diminui a criminalidade, não passa de uma falácia, uma crença, não passando de um modelo simplificador que em nada contribui para o controle da criminalidade, além de funcionar como um fator responsável por manipular o medo do delito (MOLINA e GOMES, 2006).

Os fatores anteriormente citados foram responsáveis por deslegitimarem a intervenção penal realizada pelo Estado e suas instituições sociais, pois as atuações preventivas e repressivas, dentro ou fora da estrutura jurisdicional do Estado, não atingem os fins desejados para os quais foram criados. A denominada intervenção penal máxima priorizada pelo Estado, e dada aos seus cidadãos como resposta adequada para os altos índices de criminalidade, não encontra amparo, funcionando apenas como uma falsa propaganda midiática para amenizar a situação. $\mathrm{O}$ atual modelo de justiça penal, no estágio em que se encontra, produz apenas uma atuação arbitrária do Estado, com uma consequente discriminação e exclusão (SALIBA, 2009).

Assim sendo, temos a clara necessidade de pensarmos na reconstrução de um modelo político criminal renovado, que seja capaz de oferecer soluções satisfatórias para conter a criminalidade. Tal reconstrução deve necessariamente passar pelos resultados obtidos pelos Juizados Especiais Criminais, levando em consideração os pressupostos restaurativos, 
procurando-se dar uma maior aplicação, e espaço, para a conciliação entre ofensor e vítima, sendo facultado a esta a oportunidade de aceitar soluções alternativas que lhe seriam úteis, atendendo aos seus interesse diretamente envolvidos no conflito (SALIBA, 2009).

A lógica instaurada no sistema vigente deve, necessariamente, ser modificada, pois é baseada em uma mantença de poder do dominante sobre o dominado, acarretando em uma exclusão, estigmatização e eliminação do outro. O sistema atual também possui uma nítida desproporcionalidade entre a pena aplicada e a conduta cometida, lembrando que nem sempre o início da persecução penal, do processo tradicional, atende aos interesses dos ofendidos, daí a importância de se oferecerem novas medidas, soluções baseadas em um modelo consensual de resolução dos conflitos (SALIBA, 2009).

Para análise de uma das alternativas de transformação, que pode ser de relevante contribuição, devemos examinar o princípio da intervenção mínima do Estado. Referido princípio encontra suas bases no pensamento de que somente as condutas mais graves, que representem uma maior lesão ao bem jurídico tutelado, não podendo ser solucionadas pelos demais ramos do direito, é que devem ser objeto de atuação do direito penal, com este representando uma última barreira para a solução do conflito. Nessa visão caberá ao aplicador da norma fazer a distinção necessária, ou seja, não deve funcionar de forma automática, desprovido de qualquer capacidade interpretativa, mas irá agir amparado pelos princípios que norteiam o processo penal, da melhor forma, aplicando a lei penal somente quando for à última alternativa. Através desse princípio, estaremos priorizando a resolução de conflitos por meios menos agressivos e, como consequencia, estaremos legitimando o sistema penal, ao restringirmos a sua atuação (SALIBA, 2009).

Reconhecidos os grandes avanços trazidos pelos Juizados Especiais Criminais, também se faz necessário o reconhecimento de que estes não conseguiram concretizar todos os ideais que se propuseram a realizar. Embora não tenhamos concretizado uma aplicação prática totalmente fiel a teoria, é preciso dar ênfase ao marco representado pela sua criação no processo penal brasileiro, rompendo com o modelo tradicional de justiça criminal, adotando novas medidas despenalizadoras, trazendo um novo paradigma para o combate a violência, que não mais se funda na mera aplicação da sanção penal ao infrator (LOPES JÚNIOR, 2016).

Um dos problemas que precisam ser encarados na busca por alternativas efetivas ao modelo tradicional de justiça criminal, é o alto índice de processos que tramitam nas varas criminais comuns. O primeiro passo em direção a uma diminuição já foi dado, com o funcionamento dos Juizados Especiais Criminais, abrangendo a tramitação dos delitos de 
menor potencial ofensivo, dando nova resolução a esse conflitos, permitindo que apenas os delitos mais graves fossem resolvidos nas varas comuns, pois estes seriam aqueles delitos que necessitam de uma efetiva atuação do Estado para a sua resolução. Foram as tentativas realizadas pela Lei $n^{\circ}$ 9.099/95, em criar inovações a um sistema já tão saturado, incorporando uma experiência mais informal, que abriu espaço no sentido de se buscar nos princípios restaurativos uma nova alternativa. E foi a partir da implantação de novos projetos de justiça que chegou-se a conclusão de que a Justiça Restaurativa é de fato o único modelo alternativo de solução de conflitos capaz de produzir uma alternativa realmente efetiva, quebrando o paradigma de que toda a prática criminosa está associada a um castigo, uma pena à ser imposta ao infrator (ACHUTTI, 2014).

Assumindo o fato de que a Justiça Restaurativa é um novo modelo para a administração dos litígios, podemos partir da premissa que sua incidência no Brasil poderá proporcionar uma significativa diminuição nos índices de encarceramento, além de ser realmente efetiva na tentativa de diminuição da reincidência, visto que a norma penal tradicional falha bastante nesse quesito (ACHUTTI, 2014).

Visto os benefícios que a aplicação da Justiça Restaurativa pode trazer para o cenário jurídico brasileiro, partiremos para a análise acerca de como poderá se dar a sua aplicação e quais as possibilidades de concretização dos seus ideais a partir dos Juizados Especiais Criminais e das experiências obtidas por meio destes.

Primeiramente, para evitar que percamos os principais pontos positivos a serem introduzidos pela Justiça Restaurativa, é necessário que modifiquemos a cultura jurídica do país. Este é um risco que não se pode permitir, visto serem os princípios restaurativos a principal diferença para o modelo tradicional hoje implementado. Nosso arcaico sistema tradicional já barrou a concretização de muitos dos ideais dos Juizados Especiais Criminais e o mesmo acontecerá com a Justiça Restaurativa no caso de nossos legisladores não mudarem o seu modo de pensar. Apesar de vermos que a Justiça Restaurativa pode ser aplicada no estágio em que se encontra o processo penal brasileiro, deve haver o questionamento acerca de se, nas atuais condições, a reforma conseguiria proporcionar os benefícios visados, e esperados pelo legislador (ACHUTTI, 2014).

Dentre as contribuições que podem ser ofertadas pela aplicação da Justiça Restaurativa, a principal delas se dá na sua flexibilidade, demonstrando um claro contraponto ao que hoje é oferecido pelo Direito Penal tradicional, que não oferece grande amparo nesse sentido. Hoje, a nossa legislação penal trabalha, majoritariamente, com o antagonismo entre as partes, vítima e infrator, não proporcionando oportunidade para um eventual consenso 
entre as partes, que poderia ser útil a ambas. Todavia, a Justiça Restaurativa através de seus princípios restauradores e, a justiça consensuada proposta pelos Juizados Especiais Criminais através da Lei no 9.099/95, quebram esse paradigma, demonstrando que é possível termos a solução de conflitos por intermédio de um modelo em que não se encontra todas as formalidades ritualísticas que permeiam o processo penal tradicional (SALIBA, 2009).

Atualmente temos a presença de vários elementos que, ainda constantes em nossa cultura jurídica, obstam a implementação de mudanças realmente significativas ao modelo vigente, e um deles se dá na situação de enxergarmos fundamentos criados a mais de duzentos anos como essenciais para a sobrevivência da sociedade como a temos hoje. Outros elementos também constituem barreiras para uma radical mudança na lógica penal vigente, como a formação de juristas completamente desvinculados da realidade social brasileira, além dos problemas enfrentados pela sociedade como um todo. Enquanto não for encontrada uma maneira para que tais obstáculos sejam superados, toda e qualquer tentativa de modificação será barrada pela lógica de uma política criminal com característica repressivista, burocrática e autoritária (ACHUTTI, 2014).

$\mathrm{Na}$ atualidade não podemos mais conceber o paradigma vigente de que realmente a infração praticada necessita receber uma sanção correspondente, conforme explica Daniel Achutti ao citar Leonardo Sica, demonstrando que não há uma necessidade coletiva de punir, mas sim um hábito de punir, enraizado na sociedade moderna e sua nova concepção de justiça. Quando estruturamos o modo de pensar acerca do direito penal e processual penal associando-os a sua característica habitual, que é a sanção privativa de liberdade, como sendo o único meio efetivo para corrigir os danos causados pela prática delitiva, estaremos legitimando o poder punitivo estatal e, consequentemente, barrando qualquer alternativa viável que possa ser instaurada. Assim, o sistema penal tradicional encontra-se autorizado a operar em seu modelo tradicional (ACHUTTI, 2014).

Para a Justiça Restaurativa operar no Direito Penal brasileiro, de forma que os seus princípios norteadores realmente ofereçam a mudança que o sistema tanto precisa, será necessário a quebra do paradigma de que as características que fundamentam o sistema penal são inegociáveis, não passíveis de receber qualquer tipo de modificação, pois desse modo, estaremos apenas criando uma justificativa racional para embasar os pensamentos as motivações pelas quais mudanças na lógica vigente não conseguem ser implementadas. Deve ficar claro que, não se trata de negar a importância ou eficiência da lógica tradicional, mas que deve-se questionar o fato de ser essa a única lógica capaz de concepção dos casos penais, 
demonstrar que essa lógica não é intocável, tampouco a única eficiente para a solução dos litígios penais (ACHUTTI, 2014).

A fim de analisarmos uma entrada da Justiça Restaurativa como alternativa ao sistema vigente, devemos também analisar as experiências obtidas com a aplicação da Lei $\mathrm{n}^{\circ}$ 9.099/95, visto que ela representa o principal passo dado nos últimos anos no caminho da implementação de um mecanismo informal de solução de conflitos. A Justiça Restaurativa e os Juizados Especiais Criminais possuem semelhanças em alguns de seus princípios, como a informalidade e a conciliação, e estes últimos auxiliaram a modificar o panorama jurídico brasileiro a partir do momento em que permitiram uma atuação menos repressiva por parte do Estado (ACHUTTI, 2014).

Um dos principais fundamentos da Justiça Restaurativa é o de trazer para os núcleos restaurativos uma maior participação da vítima, visando melhor atender os seus interesses, é também com esse intuito que houve a criação dos Juizados Especiais Criminais, objetivando tratar a punição com última via, abrindo espaço para o diálogo entre vítima e infrator, tentando atender aos seus interesses para que ambos pudessem sair satisfeitos da resolução, tendo os seus interesses sido efetivamente atendidos. $\mathrm{O}$ autor Daniel Achutti cita Ada Pellegrini Grinover informando que para esta, a criação dos Juizados Especiais Criminais representa uma clara vontade do legislador de dar uma nova alternativa, uma nova solução para os delitos de pequeno e médio potencial ofensivo. Apesar da resistência da sociedade atual em mudar o modo de pensar, reconhecendo que a punição não é o único caminho para a solução dos litígios de natureza criminal, a criação da Lei no 9.099 demonstra que o legislador encontra-se de acordo com as tendências internacionais, sendo uma boa abertura para que, futuramente, a Justiça Restaurativa possa ser regulamentada no Brasil (ACHUTTI, 2014).

Nem tudo foi positivo na aplicação prática da Lei $\mathrm{n}^{\circ}$ 9.099, apesar de trazer alguns princípios restaurativos, estes não tiveram sucesso na sua aplicação prática por intermédio dos Juizados Especiais Criminais. A reparação dos danos sofridos pela vítima, um dos principais princípios restaurativos, não foi devidamente implementada no Juizado Especial Criminal, tornando-se não buscada na ampla maioria dos casos submetidos aos juizados. Na prática, o objetivo de diminuir os processos que tramitavam nas varas criminais comuns não foi atingido, havendo, de certa forma, um aumento nos processos que tramitavam nestas, processos que, antes da edição da Lei $\mathrm{n}^{\circ}$ 9.099, sequer seriam submetidos para a análise do Poder Público. Muito disto se deve ao fato de que os Juizados Especiais Criminais falharam no seu principal objetivo, o de promover a conciliação entre as partes, não se importando com a forma pela qual esta iria ocorrer (ACHUTTI, 2014). 
Diferentemente dos núcleos restaurativos, em que ocorre a efetiva participação da vítima na solução do conflito, na prática do Juizado Especial Criminal, isto permaneceu apenas no plano teórico, com as vítimas demonstrando grande insatisfação e não havendo o necessário incentivo ao diálogo para que vítima e desviante viessem a obter uma conciliação. Uma das razões pela qual os Juizados Especiais Criminais não conseguiram promover a reparação do dano sofrido pela vítima se deve a máxima efetividade exigida dos juízes que neles operam, que aliado ao princípio da celeridade, um dos pilares da Lei $\mathrm{n}^{\circ}$ 9.099, terminaram por obstruir a construção de um diálogo entre vítima e infrator capaz de promover a conciliação entre as partes. Desta forma, tivemos a criação de uma lei que aparentemente privilegia o consenso entre as partes, mas que na prática não conseguiu livrar-se do sistema burocratizado já implementado pelo poder estatal. Apesar de os Juizados Especiais terem trazido para apreciação do Poder Judiciário conflitos que anteriormente não eram levados à sua jurisdição, isto não foi de todo negativo, não podemos enxergar apenas como um aumento no trâmite de processos que percorrem a máquina judiciária diariamente. Esse aumento representa um significativo salto no acesso à justiça, com uma grande parcela da população, que antes não tinha os seus conflitos analisados pelo Poder Judiciário, passando a ter a apreciação dos seus litígios (ACHUTTI, 2014).

Para haver uma efetiva mudança no modelo de solução de conflitos com a inserção da Justiça Restaurativa no ordenamento jurídico, será necessário analisar as experiências obtidas com a prática dos Juizados Especiais Criminais, vislumbrando seus erros e acertos, pois somente assim teremos uma verdadeira alteração, não deixando que os mecanismos penais clássicos possam obstruir uma real aplicação da Justiça Restaurativa, aniquilando alguns de seus principais princípios e fundamentos para que ocorra sua real aplicação. Lembra-se que os Juizados Especiais Criminais também pretendiam implementar algumas das principais características do procedimento restaurativo, como a maior participação da vítima e a conciliação entre as partes, mas que acabaram sucumbindo em virtude da não superação dos mecanismos penais que barraram a sua aplicabilidade, ficando apenas no campo teórico. Essas mudanças somente terão o seu verdadeiro efeito quando se desvincularem de determinadas engrenagens do sistema tradicional, caso contrário, estarão reproduzindo todos os seus vícios que, consequentemente, levaram a crise existente hoje (ACHUTTI, 2014).

Deixamos claro que, as experiências obtidas com a aplicabilidade da Lei $n^{\circ}$ 9.099, contribuem, e muito, para uma futura regulamentação da Justiça Restaurativa no Brasil, mas que é preciso editar uma normatização que traga os principais elementos para ocorrer a implantação da estrutura necessária dos núcleos restaurativos, visando a sua eficiente 
aplicação. Essa lei deve deixar de lado a linguagem criminalizadora do direito penal tradicional, exigindo a intervenção dos operadores do direito, pois em contrário, correremos o risco de sucumbir o potencial restaurativo. A lei responsável por regulamentar a Justiça Restaurativa deve ser clara ao estabelecer a sua diferença se comparada à justiça penal tradicional, mas não deve ser omissa no que diz respeito à forma de como ambos os sistemas irão se entrecruzar, demonstrar como a Justiça Restaurativa irá complementar o sistema atual (ACHUTTI, 2014).

A importância acerca da forma como ambos os sistemas de justiça irão se entrecruzar é devido ao princípio de que a Justiça Restaurativa não defende a completa eliminação do Direito Penal atual, mas prega a sua reforma, propondo-se a reformá-lo sem que ocorra a sua eliminação. Não podemos afastar a atividade jurisdicional da solução dos conflitos, pois esta constitui princípio fundamental de qualquer Estado Democrático de Direito. Ressalta-se que os acordos restaurativos obtidos por meio dos núcleos de Justiça Restaurativa, podem ser revistos pelo Poder Judiciário a requerimento de qualquer das partes, do Ministério Público, do advogado ou do defensor público, reafirmando o fato de que as garantias constitucionais também se encontram previstas nesse modelo de justiça. Fica, dessa forma, evidente a necessidade de se revisar os aparatos da justiça penal tradicional e assim, construírem-se, novamente, os Direitos e garantias que hoje acabam por ser violados diante da crise enfrentada pelo sistema (SALIBA, 2009).

Assim sendo, a Justiça Restaurativa deve ser promovida pelos governos, com estes a apresentando como resposta para a criminalidade, promovendo políticas públicas que visem à reparação do dano e a integração do indivíduo desviante na sociedade, prezando pela dignidade de ambas as partes, vítima e ofensor privilegiando os seus interesses na resolução dos litígios. A lei responsável pela implantação da Justiça Restaurativa redefinirá o conceito de crime a partir de uma nova visão trazida pelos princípios restaurativos, implementando um sistema que, verdadeiramente, busca conhecer a verdade e não apenas torna o legislador um mero aplicador de sanções penais (LEAL, 2014).

Diferentemente do que ocorreu com a edificação da Lei $\mathrm{n}^{\circ}$ 9.099, a Justiça Restaurativa deve ser implementada como um novo modelo de justiça criminal, visando complementar o arquétipo tradicional e assim fazê-lo mais eficiente, aperfeiçoá-lo em um contexto geral. Nos Juizados Especiais Criminais houve uma denominada falha em seu projeto, como explica Daniel Achutti ao citar o posicionamento de Leonardo Sica, afirmando que para este os Juizados Especiais, por meio dos princípios da celeridade e simplificação da justiça, visaram apenas um processo de alcançar resultados mais eficientes, solucionando 
litígios penais de uma forma mais rápida, esquecendo-se do motivo real para o qual foram criados: trazer um novo modelo de justiça criminal para complementar e desfindar problemas de um sistema tradicional arcaico que se encontrava em crise. Partindo dessa resolução, tivemos apenas atingido o objetivo administrativo do Poder Judiciário, arquivando e encerrando o maior número de processos possíveis (ACHUTTI, 2014).

Para haver a mudança devemos passar a ter um Direito Penal pautado pelos princípios da dignidade da pessoa humana, pois somente moldando o sistema punitivo por meio deste, estaremos construindo, de fato, um Estado Democrático de Direito. Quando deixamos de lado a dignidade da pessoa humana, desrespeitamos a nossa Constituição Federal, prejudicando a interpretação que possa ser dada a real finalidade da pena. Os operadores do direito possuem o dever de adequar o direito penal a realidade aonde ele será aplicado, sempre balizando suas atividades por intermédio dos direitos e garantias do indivíduo, visto que estes possuem a capacidade para limitar o poder punitivo estatal (SALIBA, 2009).

Portanto, a primeira atitude para a implantação de uma profunda reforma no sistema penal vigente deve ser a de promoção de novos instrumentos capazes de suprir a insuficiência do modelo tradicional, e esses mecanismos devem proporcionar ao Direito Penal vigente uma melhor forma de administração dos conflitos. Ressalta-se que tais engrenagens precisam ser efetivadas depois de realizados debates acerca do tema, onde se vislumbre a necessidade de modificação de um sistema que, talvez, nunca tenha produzido resultados realmente satisfatórios, que propiciassem aos seus cidadãos uma resposta adequada para a criminalidade enfrentada ao longo dos tempos (ACHUTTI, 2014).

A Justiça Restaurativa representa a alternativa inteligente que o sistema merece e precisa, ajudando por meio dos mecanismos conciliatórios e, que propiciam maior participação da vítima e da comunidade do que os ofertados pelo sistema criminal tradicional, de modo a melhor resolver os seus conflitos, auxiliando, por conseguinte, na sua administração. A experiência obtida por meio da aplicação dos Juizados Especiais Criminais proporciona muitos aprendizados, demonstrando o modo pelo qual os operadores do direito devem realizar a regulamentação da Justiça Restaurativa. Os erros cometidos com os Juizados Especiais não mais podem se repetir, não podemos perder os principais pontos da mudança proposta relegando-os ao plano teórico, deixando a máquina do poder estatal suprimir, novamente, a participação da vítima, impossibilitando a efetivação dos mecanismos conciliatórios e reparatórios que visam a satisfação dos seus interesses. Caso não aprendamos com as experiências do passado, correremos o risco de, outra vez, perder um excelente modelo de resolução de conflitos, deixando passar novamente a oportunidade de realizar a 
mudança profunda no Direito Penal tradicional, que há muito tempo é pedida pelo sistema (ACHUTTI, 2014).

\section{Conclusão}

O propósito deste trabalho foi o de demonstrar a contribuição que os princípios e os ideais da Justiça Restaurativa podem dar para o sistema criminal tradicional, tendo por base a análise acerca do conceito de justiça, analisando o conceito de justiça adotado pelo nosso Código Penal, explanando quais as situações em que ainda se faz necessário e em quais aspectos é preciso haver uma reformulação. Para a defesa da inserção dos ideais restaurativos no Direito Penal atual, primeiro foi necessário assumir e demonstrar a crise pela qual o sistema atravessa, não possuindo mais a capacidade de atender aos desejos e anseios dos cidadãos, principalmente da vítima do comportamento desviante, pois esta foi relegada pelo sistema a um papel secundário, com o Estado, através dos tempos, tendo assumido a condição de principal afetado pela prática delituosa. Antes de se aprofundar no estudo de novas alternativas de mudança, é preciso assumir que o sistema precisa ser modificado, vislumbrando suas falhas para que possam ser corrigidas, e assim se desenhe o caminho pelo qual as alternativas precisam e, devem ser implantadas.

O estudo acerca dos avanços trazidos pelos Juizados Especiais Criminais teve como finalidade demonstrar a semelhança de alguns de seus princípios com a Justiça Restaurativa, estabelecendo que essa não é a primeira a apresentar tais propósitos de mudança para o sistema, a Justiça Restaurativa não é a primeira alternativa a defender a inclusão da vítima, dando uma maior participação a esta no processo penal. Os Juizados Especiais Criminais, por intermédio da sua regulamentação com a Lei nº 9.099/95, nos mostra que o legislador, desde há certo tempo, enxerga a necessidade de haverem mudanças, isso se deu no momento em que foi fornecido um novo tratamento aos crimes de menor potencial ofensivo pelos Juizados. Apesar de os Juizados terem significado um novo avanço em direção a implementação de uma justiça conciliatória, propiciando a vítima uma maior participação e ao desviante um tratamento com maior dignidade, estabelecendo ser a pena privativa de liberdade a última alternativa, muitos de seus ideais permaneceram apenas no plano teórico, não sendo devidamente trabalhados na prática dos Juizados Especiais Criminais no Poder Judiciário.

Os acertos cometidos com os juizados nos permite ver o caminho a ser seguido com uma futura regulamentação da Justiça Restaurativa, enquanto que os erros nos demonstram como não deixar que esse novo modelo de justiça torne-se apenas mais um aparato 
melhorando apenas a parte administrativa do Poder Judiciário, diminuindo o número de processos que tramitam diariamente nas varas criminais comuns.

O presente trabalho pretendia defender a Justiça Restaurativa como a mais eficiente alternativa a ser incorporada pelo sistema criminal tradicional, pois sua contribuição no trato as vítimas e ao ofensor, em conjunto com a participação da comunidade, permite dar uma nova solução para os conflitos que ocorrem diariamente e que não são devidamente solucionados pelo Direito Penal tradicional. Lembrando sempre que a Justiça Restaurativa não pretende, e nem defende, a completa eliminação do sistema criminal tradicional, mas deseja complementá-lo, sendo a alternativa que visa corrigir as falhas que o sistema, sozinho, não é capaz de solucionar. Apesar de haverem posicionamentos contrários, o entendimento é dominante de que os ideais restaurativos tendem a muito contribuir na prática penal tradicional, solucionando problemas que a muito pedem correção.

A implementação dos Juizados Especiais Criminais no ano de 1995, ampliado no espectro da Justiça Federal com a edição da Lei 10.259/01, representaram um primeiro passo a ser dado em direção a uma justiça penal mais humana, deixando de lado a visão de que o Direito Penal máximo, dando uma maior rigorosidade para o tratamento das infrações praticadas, é o caminho a ser seguido. Neste momento um novo passo precisa ser dado nesse sentido, visto que apenas o trabalho dos Juizados não foi suficiente. A Justiça Restaurativa, com efeito, se propõe a ser esse novo passo, a ser essa nova alternativa de complementação a um sistema arcaico que, não mais, consegue ser totalmente eficiente na solução dos litígios que são submetidos a sua jurisdição.

\section{Referências}

ACHUTTI, Daniel Silva. Justiça restaurativa e abolicionismo penal. São Paulo: Saraiva, 2014.

DEMERCIAN, Pedro Henrique; MALULY, Jorge Assaf. (1960). Teoria e prática dos juizados especiais criminais Rio de Janeiro: Forense, 2008.

FERRAJOLI, Luigi. Direito e razão: teoria do garantismo penal. Tradução de Ana Paula Zolmer, Fauzi Hassan Choukr, Juarez Tavares e Luiz Flávio Gomes. São Paulo: Revista dos Tribunais, 2002, p. 310.

LEAL, César Barros. Justiça restaurativa amanhecer de uma era: aplicação em prisões e centros de internação de adolescentes infratores. Curitiba: Juruá, 2014.

LOPES JUNIIOR, Aury. Direito processual penal. 13. ed. São Paulo: Saraiva, 2016. 
MOLINA, Antonio García-Pablos de; GOMES, Luiz Flávio. Criminologia: introdução a seus fundamentos teóricos; introdução às bases criminológicas da Lei 9.099/95, Lei dos Juizados Especiais Criminais. 5. ed. rev. atual. São: Revista dos Tribunais, 2006.

SALIBA, Marcelo Gonçalves. Justiça restaurativa e paradigma punitivo. Curitiba: Juruá, 2009.

VAN NESS, Daniel W.; STRONG, Karen Heetderks. Restoring Justice: an introduction to Retorative Justice. 4.ed. New Providence, NJ: LexisNexis, Anderson Publishing, 2010. 